\title{
Stroke in Maputo Central Hospital, Mozambique 2019: A Glimpse of Epidemic or Endemicity?
}

\author{
Yanina Baduro ( $\nabla$ yaninamunira@gmail.com ) \\ Hospital Central de Maputo \\ Omer Ndala \\ Hospital Central de Maputo \\ Deise Vaz \\ Hospital Central de Maputo \\ Helena Buque \\ Hospital Central de Maputo \\ Frederico Sebastião \\ Hospital Central de Maputo \\ Jamal Baco \\ Hospital Central de Maputo \\ Nachan Arroz \\ Hospital Central de Maputo \\ Carlos Casas \\ Hospital Central de Maputo \\ Elder Lorenzo \\ Hospital Central de Maputo \\ Jorge Arroz \\ https://orcid.org/0000-0001-6604-4573
}

\section{Research note}

Keywords: Stroke, Epidemics, Endemic Channel, Cross-sectional study, Maputo Central Hospital, Mozambique

Posted Date: August 9th, 2019

DOl: https://doi.org/10.21203/rs.2.12569/v1

License: (c) (i) This work is licensed under a Creative Commons Attribution 4.0 International License. Read Full License 
Version of Record: A version of this preprint was published at Journal of the Neurological Sciences on October 1st, 2019. See the published version at https://doi.org/10.1016/j.jns.2019.10.741. 


\section{Abstract}

Objective

The aim of this study is to determine the endemic/epidemic pattern of stroke in Maputo Central Hospital in the first semester of 2019.

Results

During the period 2014-18, there were 2,979 registered cases of stroke in $\mathrm{MCH}$, ranging from 512 in 2017 and 687 in 2015. The mean monthly registered cases per year ranged from 43 in 2017 to 57 in 2015. The C-SUM+1.96SD and mean+2SD methods have the highest monthly thresholds comparing to C-SUM and 3rd quartile methods. An epidemic pattern of stroke was observed during the first semester of 2019 when 3rd quartile and C-SUM threshold epidemic method was used. A relatively stable pattern of stroke occurrence with high registered cases was observed during the study period. It can be concluded that stroke is an endemic disease for the Maputo Central Hospital, with an epidemic pattern during the first semester of 2019. Adoption of 3rd quartile threshold methods for stroke surveillance might well add value for the control of the stroke epidemics.

\section{Introduction}

Stroke (cerebrovascular accident) is a noncommunicable disease (NCD) currently recognized as a major leading cause for reduced life expectancy at birth globally for men and women. According to World Health Organization, stroke mortality rates are higher in males, and the reduced life expectancy of males compared with that of females is not due to a single or a small number of causes [1]. The five main causes of death that contribute to a lower life expectancy in males than in females are ischemic heart disease, road injuries, lung cancers, chronic obstructive pulmonary disease and stroke [1].

Although not a communicable disease, the term "stroke epidemic" is being used widely in the literature [2 6]. Two terms predominantly used for infectious diseases are herein important to recall: "epidemic" and "endemic". Epidemic is defined as the occurrence in a region or community of a number of excess cases, in relation to what would normally be expected; diseases are called endemic when in a geographical area or population group it presents a relatively stable pattern of occurrence with high incidence or prevalence [7].

Even if NCDs are non-infectious diseases, they may spread due to the social transmission of unhealthy activities such as unhealthy diet, physical inactivity, and smoking [8]. Therefore, stroke with his potential of social transmission of unfavorable social determinants of health, allowed us to borrow the "epidemic" and "endemic" terminology from infectious disease to describe certain occurrence and trends in a particularly geographical area. 
The last published article on stroke in Mozambique is dated from 2010. The study shows crude and adjusted (world reference population) annual incidence rates of stroke of 148.7 per 100,000 and 260.1 per 100,000 aged 25 years, respectively-data from Maputo Central Hospital, 3 general public hospitals, the Military Hospital, and 6 private clinics [9]. Despite these rates, there is a gap of knowledge to determine if stroke is endemic or epidemic in Maputo Central Hospital.

The aim of this study is to determine the endemic/epidemic pattern of stroke in Maputo Central Hospital in the first semester of 2019.

\section{Methods}

\section{Context}

Maputo Central Hospital (MCH) is located in the city of Maputo (capital of Mozambique). Is a quaternary level hospital (the highest level in Mozambique) and is a national reference hospital. The direct catchment-population of the $\mathrm{MCH}$ is around 3 million inhabitants, and the indirect catchment-population is around 29 million inhabitants.

\section{Study Design}

A cross-sectional hospital-based study was carried out in 2019 , collecting secondary data (registered cases) from hospitalized patients with stroke from the years 2014-18, and first semester of 2019. All the Medicine wards (who admit stroke patients) from $\mathrm{MCH}$ were selected for the study data collection.

\section{Building the endemic channel: Thresholds methods}

Four threshold epidemic detection methods were used, namely: i) monthly mean for the past five years plus two times the standard deviation (mean + 2SD); ii) cumulative sum method (C-SUM), which is the mean calculated over the combined previous, current and following months' data for the past five years; iii) C-SUM + 1.96SD; and iv) the 3rd quartile, which is the second highest value noted for the month over the past five years.

\section{Description of the threshold methods}

Mean + 2SD: uses the previous five years' data to construct an admissions profile for an average year at that location. The alert threshold for each month is then determined as the mean plus two times the standard deviation.

C-SUM: is based on the construction of an average or base year by calculating the expected number of cases using the average for that month (and the previous and following month) during the past five 
years.

C-SUM + 1.96SD: is based on C-SUM method refined by adding a $95 \%$ confidence interval.

Third quartile: is based on the using of $3^{\text {rd }}$ quartile for each month during the past five years. If the current month's cases exceed quartile 3 , an alarm is triggered-epidemic zone.

\section{Outcomes of interest}

The main outcomes are: (i) stroke cases and percentage per month per year (2014-18); (ii) monthly stroke threshold for the period 2014-18; (iii) stroke cases from January to June 2019.

\section{Statistical analysis}

Monthly stroke data from the period 2014-18 and January to June 2019 were collected from the Medicine wards registry books. These monthly data were introduced in a Microsoft ${ }^{\circledR}$ Office Excel® 2007 spreadsheet for organization, analysis and storage of data in tabular form. Monthly data from 2014-18 were used to calculate the percentage, mean and SD of registered stroke cases and to generate the epidemic thresholds. Data from January to June 2019 were used to analyze the 2019 trend over the thresholds. Graphics were generated to better illustrate the thresholds and for tracking first semester 2019 .

\section{Results}

\section{Registered stroke cases and percentage per month per year (2014- 18)}

During the period 2014-18, there were 2,979 registered cases of stroke in $\mathrm{MCH}$, ranging from 512 in 2017 and 687 in 2015. The mean registered stroke cases per year were 596. The mean monthly registered cases per year ranged from 43 in 2017 to 57 in 2015-Table 1.

\section{Monthly stroke threshold and the trend in 2019}

The monthly threshold constructed based on the four models shows a relatively stable pattern over the months, although with some fluctuations between the models. The C-SUM+1.96SD and mean+2SD methods have the highest monthly thresholds comparing to C-SUM and $3^{\text {rd }}$ quartile methods. The minimum monthly threshold was 47 registered stroke cases in March for the C-SUM method, and the maximum monthly threshold was 92 registered stroke cases in December for the mean+2SD methodFigure 1. 
The monthly registered stroke cases for 2019 shows an epidemic pattern for the $3^{\text {rd }}$ quartile and C-SUM method-Figure 2. No epidemic pattern was observed in 2019 with the C-SUM+1.96SD method. An epidemic month (March) was observed in 2019 with the mean+2SD method-Figure 2.

\section{Discussion}

This study showed that cases of stroke recorded in the period 2014-18 show an endemic pattern, with a relatively stable and high pattern of admitted cases in $\mathrm{MCH}$. An epidemic pattern is also observed when the $3^{\text {rd }}$ quartile and C-SUM epidemic threshold methods is used.

These endemic and epidemic patterns can be partially explained by the following factors: i) increase in hypertension prevalence and low awareness, treatment and control among hypertensive patients; ii) increase in others modifiable risk factors; iii) better health services and access to $\mathrm{MCH}$.

\section{Hypertension}

It is well known that hypertension is a major risk factor for stroke. The prevalence of hypertension in Mozambique increased from $33.1 \%$ in 2015 to $38.9 \%$ in 2014/2015 [10]. However, despite this increase, the awareness, treatment, and control among hypertensive patients remained extremely low, with $15 \%$, $7 \%$, and 3\%, respectively [10]. The May Measurement Month initiative implemented in 2017 in Mozambique also revealed high proportion of hypertension (31.1\%) among screened participants with very few in treatment and more than half of those in treatment were uncontrolled [11]. These low levels of awareness, treatment and control might be part of the triggers for an increase risk of stroke and the observed patterns in this study.

\section{Increase in others modifiable risk factors}

The increased prevalence and patterns of smoking habits (39.9\% in men and $18.0 \%$ in women) [12], insufficient physical activity (6\%) [13], Overweight and obesity $(30.1 \%$ and $11.5 \%$ in urban areas, respectively) [14], alcohol use (57.7\% in men and $28.9 \%$ in women) [15], among others modifiable risk factors in Mozambicans might additionally contribute for the occurrence of stroke events.

\section{Better health services and access to $\mathrm{MCH}$}

The availability of Computerized Tomography Scan (since 2007) and Magnetic Resonance Imaging in $\mathrm{MCH}$ may have contributed to an improvement in the services provided for the diagnosis of stroke. Awareness that $\mathrm{MCH}$ have these technologies could have been exerted a confidence demand effect for first-care. Additionally, the improvement of the health information registration system can also contribute for the increase in registered cases, and the occurrence of the observed patterns. These factors cannot be discarded as contributing for the endemic and epidemic patterns observed in this analysis. 


\section{Conclusions}

The endemicity of stroke pattern for the Maputo Central Hospital might offer a glimpse of what might happening in the hospitals of Maputo city or even in Mozambique. The observed epidemic pattern during the first semester of 2019 might be a result of the interaction of several risk factors that are increased or increasing due to over time social transmission of unfavorable health determinants. Although bold, temporarily adoption of threshold epidemics methods for stroke surveillance might well add value for the control of the stroke epidemics. The authors look forward to seeing other countries' experiences using thresholds methods for stroke surveillance.

\section{Limitations}

\section{Reliability of the models}

There is no threshold epidemic methods developed for NCDs, and therefore the authors used models tested for infectious disease (specifically malaria). Although this can be seen as a limitation, the available models for infectious disease can be temporarily used for surveillance purpose in the absence of more reliable and specific model for stroke and NCDs threshold detection. The $3^{\text {rd }}$ quartile threshold method showed more reliable for epidemic prediction when compared to the other methods. Therefore, the authors propose the use of this method for temporary surveillance of stroke in $\mathrm{MCH}$.

Another limitation of this study is the fact that duplicates admissions raise problems in determining incidence rates. Despite these limitations, the study can be the first step to raise awareness for stroke surveillance in $\mathrm{MCH}$, or even in Mozambique.

\section{Declarations}

\section{List of abbreviations}

C-SUM-Cumulative sum method; $\mathrm{MCH}-$ Maputo Central Hospital; NCD-Noncommunicable disease; SDStandard Deviation

\section{Ethics approval}

The study received authorization from the Institutional Committee on Bioethics in Health - Faculty of Medicine / Maputo Central Hospital (CIBS FM\&HCM/106/2018).

\section{Consent for publication}

Not applicable. 


\section{Availability of data and materials}

The datasets used and/or analysed during the current study are available from the corresponding author upon reasonable request.

\section{Competing interests}

The authors declare that they have no competing interests.

\section{Authors' contributions}

The "first-last-author-emphasis" (FLAE) norm combined with "sequence-determines-credit" (SDC) norm was applied for the sequence of authors. YB and JAHA conceived and designed the protocol, collected the data, and wrote the manuscript. JAHA additionally performed data analysis. ON, DV, HB, FS, JB, NA, $\mathrm{CC}$ and EL contributed to manuscript writing and revision. All authors read and approved the final manuscript.

\section{Acknowledgements}

The authors would like to acknowledge the Maputo Central Hospital authorities for the administrative authorization for the study.

\section{Funding}

Not applicable.

\section{References}

1. WHO. World health statistics overview 2019: monitoring health for the SDGs, sustainable development goals. Geneva: World Health Organization; 2019. Available from: https://apps.who.int/iris/bitstream/handle/10665/311696/WHO-DAD-2019.1-eng.pdf [Accessed July 10, 2019].

2. Feigin VL. Stroke in developing countries: can the epidemic be stopped and outcomes improved? The Lancet Neurology 2007; 6(2): 94-97.

3. Feigin VL. Public health strategies could reduce the global stroke epidemic. The Lancet Neurology 2010; 9(9): 847-848.

4. Kim AS, Johnston C. Temporal and Geographic Trends in the Global Stroke Epidemic. Stroke journal 2013; 44[suppl 1]:S123-S125. 
5. Li WA, Geng X and Ding Y. Stroke is a global epidemic: new developments in clinical and translational cerebrovascular diseases research. Neurological Research 2017; 39(6): 475-476,

6. Verma R. Stroke: A Neglected Epidemic in India. Journal of Neurosciences in Rural Practice 2018; 9(4): 453-453.

7. Bonita R, Beaglehole R, Kjellström T. Basic Epidemiology, 2nd edition. World Health Organization, 2006.

8. Goulao C, Pérez-Barahona A. Intergenerational transmission of non-communicable chronic diseases. 2012. hal-00690325. Available from: https://hal.archives-ouvertes.fr/hal-00690325/document [Accessed July 10, 2019].

9. Damasceno A, Gomes J, Azevedo A, Carilho C, Lobo V, Lopes H, et al. An epidemiological study of stroke hospitalizations in Maputo, Mozambique: A high burden of disease in a resource-poor country. Stroke. 2010, 41: 2463-2469.

10. Jessen N, Damasceno A, Silva-Matos C, Tuzine E, Madede T, Mahoque R, et al. Hypertension in Mozambique: trends between 2015 and 2015. Journal of Hypertension. 2017, 35.

11. Jessen N, Govo V, Calua E, Machava M, Fabula A, Novela C, et al. Blood pressure screening in Mozambique: the May Measurement Month 2017 project-Sub-Saharan Africa. European Heart Journal Supplements, 2019; 21: 80-82. Available from:

https://academic.oup.com/eurheartjsupp/article/21/Supplement_D/D80/5476838 [Accessed July 11, 2019].

12. Araujo C, Silva-Matos C, Damasceno A, Gouveia ML, Azevedo A, Lunet N. Manufactured and handrolled cigarettes and smokeless tobacco consumption in Mozambique: regional differences at early stages of the tobacco epidemic. Drug Alcohol Depend. 2011; 119(3):e58-e65. doi: 10.1016/j.drugalcdep.2011.05.031.

13. Thornton J. A quarter of people are not being active enough to stay healthy. BMJ 2018; 362:k3796.

14. Gomes A, Damasceno A, Azevedo A, Prista A, Silva-Matos C, Saranga S, Lunet N. Body mass index and waist circumference in Mozambique: urban/rural gap during epidemiological transition. Obes Rev. 2010;11(9):627-634. doi: 10.1111/j.1467-789X.2010.00739.x.

15. Padrao P, Damasceno A, Silva-Matos C, Laszczynska O, Prista A, Gouveia L, Lunet N. Alcohol consumption in Mozambique: regular consumption, weekly pattern and binge drinking. Drug Alcohol Depend. 2011;115(1-2):87-93.

\section{Table}

Due to technical limitations, Table 1 is only available as a download from the Supplementary File section.

\section{Figures}




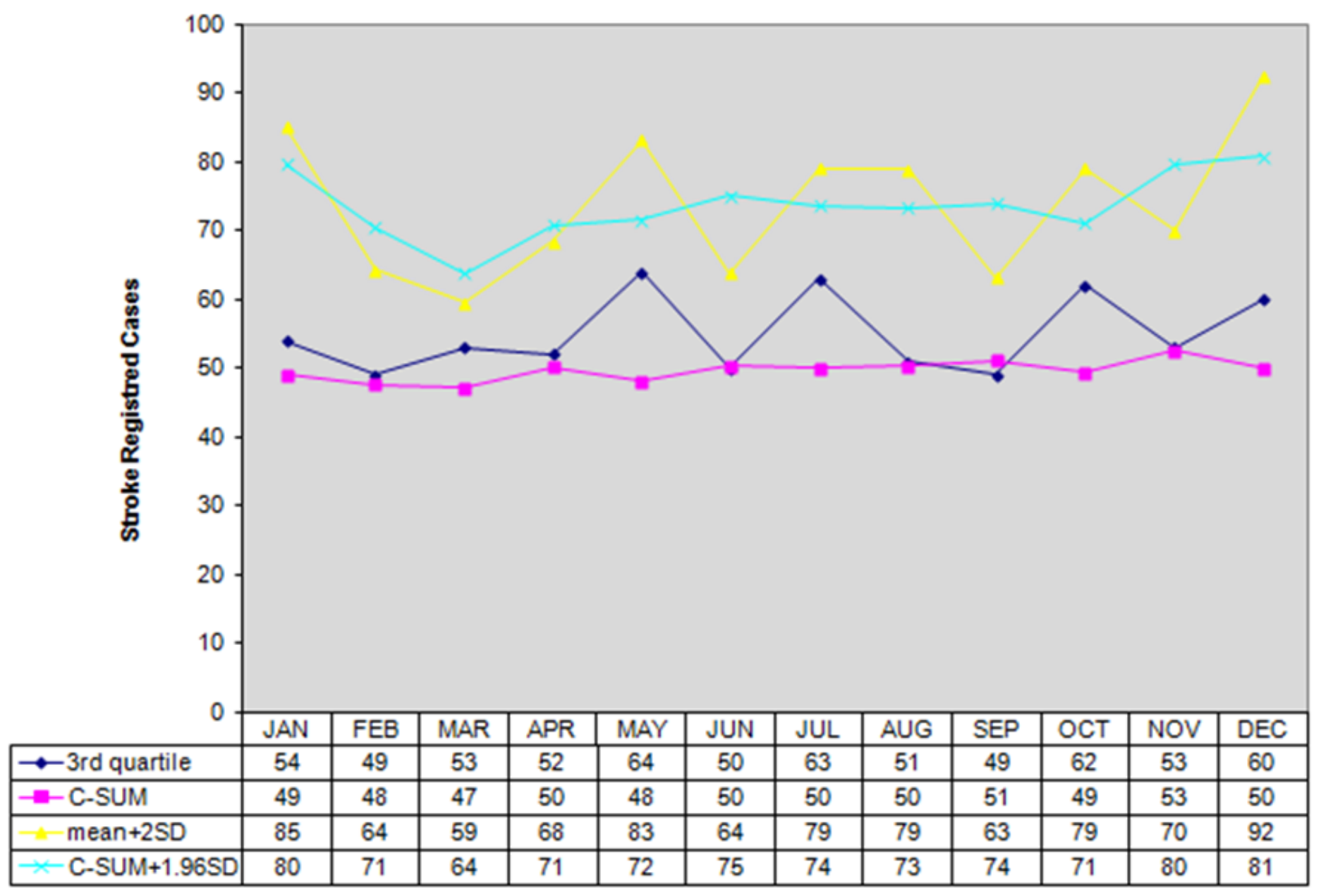

Figure 1

Monthly thresholds of registered stroke cases with the four detection methods. 


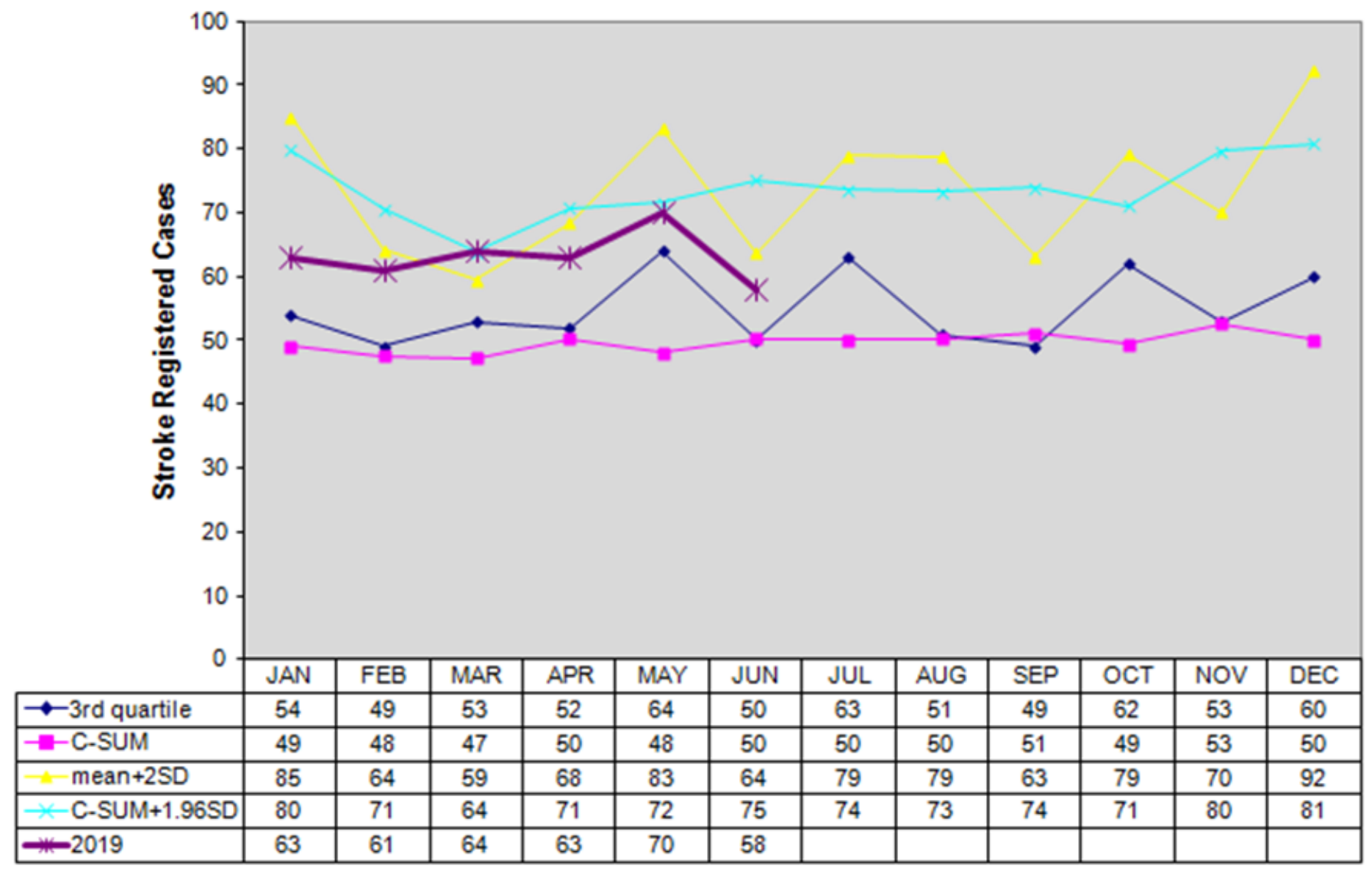

\section{Figure 2}

Monthly thresholds of registered stroke cases with the four detection methods and first semester 2019 registered stroke cases.

\section{Supplementary Files}

This is a list of supplementary files associated with this preprint. Click to download.

- Table1.png 